\title{
Long-Term Multimodal Therapy (Verapamil Associated with Propolis, Blueberry, Vitamin E and Local Diclofenac) on Patients with Peyronie's Disease (Chronic Inflammation of the Tunica Albuginea). Results of a Controlled Study
}

\author{
Gianni Paulis ${ }^{*}, 1,4$, Giorgio Cavallini ${ }^{2}$, Giovanni De Giorgio ${ }^{3,4}$, Salvatore Quattrocchi ${ }^{4}$, \\ Tommaso Brancato ${ }^{5}$ and Rosaria Alvaro ${ }^{6}$ \\ ${ }^{1}$ Andrology Center, Regina Apostolorum Hospital, Albano L., Rome, Italy \\ ${ }^{2}$ Gynepro Medical Team, Via Tranquillo Cremona 8, 44137 Bologna, Italy \\ ${ }^{3}$ Jewish Hospital, Rome, Italy \\ ${ }^{4}$ Castelfidardo Medical Team, Via Castelfidardo 34, 00185 Rome, Italy \\ ${ }^{5}$ Complex Operative Unit of Urology, Regina Apostolorum Hospital, Albano L., Rome, Italy. \\ ${ }^{6}$ Department of Public Health and Cellular Biology, University of Rome "Tor Vergata", Rome, Italy
}

\begin{abstract}
Objective: to demonstrate the possible effectiveness of a long-term multimodal medical therapy in patients with Peyronie's disease (PD) we carried out a controlled study on 82 patients diagnosed with PD, whereas in the scientific literature the conservative treatment of this disease is much discussed.

Methods: 82 patients (mean age=53.6 \pm 10.1 years-range 23-68) diagnosed with $\mathrm{PD}$ were selected for this study. Of these 41 patients (group A) were treated for 18 months as follows: Verapamil penile injections (12 total injections for six months and subsequently every month for twelve months: total 24 injections) + Iontophoresis with Verapamil/daily + blueberries $160 \mathrm{mg} /$ daily + propolis $600 \mathrm{mg}$ /daily + Vitamin E $600 \mathrm{mg} /$ daily + topical Diclofenac/daily. The other 41 patients spontaneously decided not to receive treatment for several motives and then were introduced as a control group B. All patients were controlled at 6- and 18-month follow up with the same diagnostic tests completed before the therapy (penile ultrasound, photograph documentation, pain scale etc.).

Results: In group A, after treatment of 6 and 18 months, the change in plaque volume consisted in volume reduction= $47.6 \%$ and $-73.6 \%$ respectively, while in group $\mathrm{B}$, the change consisted of an increase in plaque volume $=+55.7 \%$ and $+118.7 \%$ respectively $(\mathrm{p}=0.000)$. In group $\mathrm{A}$, after treatment of 6 and 18 months, improvement of curvature occurred in $76.3 \%$ and $81.5 \%$ of the cases respectively, while in group B it occurred in $2.7 \%$ and $8.1 \%$, respectively $(\mathrm{p}<0.0001$ ).

Conclusion: Our results showed that a long-term multimodal medical therapy (Verapamil associated with Antioxidants and local Diclofenac) is statistically effective to treat PD patients, if we consider that lower therapeutic outcomes were achieved after 6 months treatment (medium-term treatment). Furthermore, this study confirms that the best treatment modality for PD is a combination therapy.
\end{abstract}

Keywords: Antioxidants, blueberry, combined therapy, Peyronie's disease, propolis, Verapamil, vitamin E.

\section{INTRODUCTION}

Peyronie's Disease $(\mathrm{PD})$ is a progressive fibrotic disorder of the penis characterized by chronic inflammation of the tunica albuginea, involving the growth of fibrous inelastic plaques in penile corpora cavernosa. Any defect in the tunica albuginea can deform the penis with a possible curvature.

Moreover, the plaques can handle full and complete expansion of the corpora cavernosa during erection. Recent studies reported a prevalence of $3.2-13.0 \%$ in adult men

*Address correspondence to this author at the Andrology Center, Regina Apostolorum Hospital, Via San Francesco, 50 - CAP 00041, Albano Laziale, Rome, Italy; Tel: +39 06932989; Fax: +39 069321138;

E-mail: paulisg@libero.it
$[1,2]$. The etiology of this disease is not well know, although in recent years, new studies propose the penile trauma as cause of the disease [3]. PD may be caused by trauma or injury to the penis usually during sexual activity, although the majority of PD-patients do not remember a traumatic event. Fibrin deposition triggers the response to wound healing [4] with the consequent phlogistic process and production of pro-inflammatory cytokines (Transforming growth factor beta-TGF- $\beta$ etc.) that lead to collagenase inhibition, collagen overproduction and increase of reactive oxygen species (ROS) levels [5], NF-kB activation (Nuclear Factor kappa-light-chain-enhancer of activated B cells) with the consequent expression of genes on specific targets (collagen, fibrin, inducible nitric oxide synthase-iNOS, fibroblast growth factor-FGF and TGF- $\beta$ ) [6, 7]. The medical therapy is indicated in the development phase of PD, in case 
of pain and for at least 12 months after the detection of the disease. Surgical treatment is indicated in case of stable disease $[8,9]$ and when PD patients are not able to have a sexual penetration due to serious penile curvature or severe erectile insufficiency [10]. Current conservative therapies include: potaba, Vitamin E, tamoxifen, propoleum (propolis), interferons, collagenase, verapamil, cortisone, superoxide dismutate, pentoxifylline, iontophoresis and Extracorporeal Shock Wave Therapy (ESWT) [11-13]. Noticing the extreme variability of the results from different conservative treatments reported in the literature, a controlled study was carried out on patients with PD treated in association with several drugs: "multimodal therapy". In particular, the effectiveness of Verapamil (injection + iontophoresis) plus several antioxidants (Vitamin E, blueberries and propolis) and topical Diclofenac was investigated. In our previous studies we achieved good results with the same multimodal therapy, but this study was done only for a medium-term treatment (six months). However, for some patients we extended the treatment for up to 18 months (reducing the frequency of penile njections of verapamil), and obtained excellent results. Thus, we decided to implement our protocol of treatment (long-term treatment) using the same multimodal therapy for larger number of cases with follow-up after 6 and 18 months.

\section{MATERIALS AND METHODS}

This is a controlled study, performed to investigate the possible effectiveness of multimodal long-term treatment in PD patients enrolled for a conservative treatment. Between January 2, 2010 and January 2, 2012, 119 PD patients were initially selected for the present study.

All 119 patients were informed of alternative surgical procedure. However, none of them accepted this surgical treatment and 63 patients had spontaneously decided not to receive any treatment.

Exclusion criteria (for all patients including those of the control group) were: previous treatment for PD; any medical therapy for sexual problems, before or during the study; administration with herbs and/or vitamins in the previous 6 months; stabilized Peyronie's disease; penile curvature incompatible with sexual intercourse; atrioventricular (AV) conduction defects; patients older than (or equal to) 70 years (possible potential negative effects of Verapamil on cardiac conduction system) [14]. From the original 56 patients who had agreed to be treated, at first 15 cases were excluded from the study for these reasons: two cases with stabilized PD; three patients treated with PDE-5 inhibitors in the 6 months prior to study; ten cases that wouldn't have guaranteed the statistical homogeneity of the two groups of patients for several reasons (type and degree of penile curvature, plaque echogenicity, plaque volume, calcification size, presence of erectile dysfunction, comorbidity). Thus, the treatment group (Group A) was formed by 41 patients.

The control group (Group B) was composed of 41 patients with PD. All patients, who have never been treated before for PD, had spontaneously decided not to receive treatment for several motives: costs of care, hope to heal, PD underestimation, distrust in the care, etc. However, all patients have agreed to be studied and visited after a period of time at follow-up. From the original 63 cases, 22 of them were excluded from the study because they wouldn't have guaranteed the statistical homogeneity of the two groups of patients (number of cases, degree and type of curvature, echogenicity and volume of the plaque etc.). All these 41 cases were observed for 18 months, evaluating the natural progression of the disease with follow-up after 6 and 18 months.

Outcome measures: More than physical examinations and medical history, all 82 patients were subjected to the following tests: photograph during erection, pain questionnaire, IIEF questionnaire (international index of erectile function), dynamic penile color-duplex ultrasound study.

The curvature was measured with a photo during maximum erection [15].

The pain was evaluated by a conventional 11-point pain Scale (VAS) [16].

The subjective evaluation of the erection was evaluated by all patients using the questionnaire IIEF [17]; the answers that we evaluated were the questions 1-5 and 15, which specifically address the aspects of Erectile Function (IIEFEF normal score: 26-30). Patients who had a total score of less than 26 were identified as having erectile dysfunction.

Penile erectile mechanism and plaque volume were assayed with dynamic echo-color Doppler sonography of the penis performed in the course of a full erection obtained using intra-cavernosal Alprostadil $\left(\mathrm{PGE}_{1}\right) 10 \mathrm{mcg}$. The ultrasound study included an evaluation of the 3 dimensions of the lesion (plaque) determining the precise location of the lesions in the penis, as well as the length, width, and thickness of the plaques [18]. Plaque volume was measured in $\mathrm{cm}^{3}$ using the ellipsoid formula that is typically used in other urogenital diseases $(\mathrm{V}=$ length $\mathrm{x}$ thickness $\mathrm{x}$ width $\mathrm{x}$ 0.52) [19-21].

All patients were controlled for a total time of 18 months and then underwent the same tests as performed prior to the treatment.

41 patients who constitute the treatment group were observed for a period of 18 months (with follow-up after 6 and 18 months) and they were treated with these substances:

Verapamil injection (penile and peri-lesional - with needle 30 Gauge) $10 \mathrm{mg}$, every two weeks (12 total injections - the first injection $5 \mathrm{mg}$ ) for six months and subsequently every month (12 total injections) for a period of 12 months (Total $=24$ injections in 18 months)

+ iontophoresis with Verapamil-5 mg / daily (excluding the day of injection), for a period of 18 months

+ blueberries $160 \mathrm{mg}$ / oral / daily - for a period of 18 months

+ propolis $600 \mathrm{mg} /$ oral / daily (on an empty stomach to facilitate absorption), for a period of 18 months

+ Vitamin E $600 \mathrm{mg} /$ oral / daily - for a period of 18 months + topical Diclofenac sodium 4\% gel / twice a day, for a period of 6 months and subsequently: daily for a period of 12 months.

To avoid episodes of hypotension or disorders in AV conduction in the case of a hypertensive patient treated with 
calcium channel blockers, it was suggested that the patient not to take the dose of such drugs on the day of the penile injection. Iontophoresis was used placing the drug Verapamil ( $5 \mathrm{mg}$ ) on the positive pole with $4 \mathrm{~mA}$ output and for 20 minutes / day.

The results of this study were subjected to statistical analysis using Primer of biostatistics (by Stanton A. Glantz) software. A statistically significant consideration was when the $p$-value was less than 0.05 . This study was carried out in accordance with the Helsinki Declaration of 1975 as revised in 1983.

\section{RESULTS}

The study involved 82 patients (mean age $=53.6 \pm 10.1$ years; range 23-68 years). In most cases (91.4\%) patients reported a penile curvature (75/82 cases). Penile pain was present in 49 patients $(59.7 \%$ of total cases) and the mean painscore (VAS) was $6.6( \pm 2.6 \mathrm{SD})$. Erectile Dysfunction (ED) was present in 21 cases $(25.6 \%$ of total cases $)$.

The two groups of this study were sufficiently homogeneous for a statistical analysis of results (patient age, comorbidities, PD duration, presence and intensity of penile pain, plaque size, calcification size, degree of curvature and presence of erectile dysfunction. Clinical characteristics, basic demographics and comorbidities related to the two groups of PD patients are listed in Table $\mathbf{1 .}$

In all cases when calcification was present, it did not exist in the whole area of the plaque, but was only present in small part, confirming that the disease was in the progressive phase.

Table 1. Clinical Characteristics and Basic Demographics of PD Patients in Both Groups

\begin{tabular}{|c|c|c|c|}
\hline Characteristics & $\begin{array}{c}\text { Treated Group Group A } \\
\text { n. } 41 \text { Cases }\end{array}$ & $\begin{array}{c}\text { No-Treated Group } \\
\text { Group B } \\
\text { n. } 41 \text { Cases }\end{array}$ & $\begin{array}{c}\text { Statistical Analysis } \\
\text { p-Value }\end{array}$ \\
\hline Mean Age (years) + Standard Deviation & $54.29 \pm 9.21$ & $53.46 \pm 10.86$ & $\mathrm{p}=0.710($ ANOVA $)$ \\
\hline Time Since PD Onset (months) + Standard Deviation & $13.00 \pm 5.7$ & $12.63 \pm 2.89$ & $\mathrm{p}=0.712($ ANOVA $)$ \\
\hline Mean Plaque Volume $\left(\mathrm{cm}^{3}\right)+$ Standard Deviation & $1.068 \pm 0.994$ & $1.040 \pm 0.728$ & $\mathrm{p}=0.885($ ANOVA $)$ \\
\hline \multicolumn{4}{|l|}{ Plaque Echogenicity / n. cases } \\
\hline Hyperechoic & 14 & 15 & $\mathrm{p}=0.817\left(\chi^{2}\right.$ test $)$ \\
\hline Hyperechoic + calcification & 9 & 10 & $\mathrm{p}=0.793\left(\chi^{2}\right.$ test $)$ \\
\hline Hypoechoic & 6 & 5 & $\mathrm{p}=0.745\left(\chi^{2}\right.$ test $)$ \\
\hline Isoechoic & 5 & 5 & $\mathrm{p}=1.0\left(\chi^{2}\right.$ test $)$ \\
\hline Inhomogeneous echogenicity (including calcification) & 7 & 6 & $\mathrm{p}=0.762\left(\chi^{2}\right.$ test $)$ \\
\hline Total number of cases with calcifications & 16 & 15 & $\mathrm{p}=0.819\left(\chi^{2}\right.$ test $)$ \\
\hline Mean Calcification Volume $\left(\mathrm{cm}^{3}\right)+$ Standard Deviation & $0.181 \pm 0.262$ & $0.196 \pm 0.289$ & $\mathrm{p}=0.877($ ANOVA $)$ \\
\hline Associated Erectile Dysfunction (ED) n. cases & 10 & 11 & $\mathrm{p}=0.800\left(\chi^{2}\right.$ test $)$ \\
\hline Erectile Function Index of PD Patients with ED Mean Score + Standard Deviation & $20.8 \pm 2.03$ & $20.54 \pm 1.91$ & $\mathrm{p}=0.766($ ANOVA $)$ \\
\hline Associated Penile Pain During Erection n. cases & 25 & 24 & $\mathrm{p}=0.821\left(\chi^{2}\right.$ test $)$ \\
\hline VAS Score of PD Patients with Penile Pain mean score + Standard Deviation & $6.8 \pm 2.66$ & $6.54 \pm 2.65$ & $\mathrm{p}=0.733($ ANOVA) \\
\hline Objective Penile Curvature cases $+\%$ cases $/$ total & 3892.68 & 3790.24 & $\mathrm{p}=0.692\left(\chi^{2}\right.$ test $)$ \\
\hline Curvature Mean degrees ${ }^{\circ}+$ Standard Deviation & $31.63^{\circ} \pm 13.48$ & $30.81^{\circ} \pm 9.65$ & $\mathrm{p}=0.763($ ANOVA $)$ \\
\hline Comorbidities & n. Cases & n. Cases & p-Value $(\chi 2$ test) \\
\hline Hypertension & 10 & 10 & $\mathrm{p}=1.0$ \\
\hline Dyslipidemia & 3 & 4 & $\mathrm{p}=0.692$ \\
\hline Ischaemic heart disease & 3 & 2 & $\mathrm{p}=0.644$ \\
\hline Diabetes & 2 & 3 & $\mathrm{p}=0.644$ \\
\hline Hypotestosteronemia & 3 & 3 & $\mathrm{p}=1.0$ \\
\hline Chronic prostatitis & 4 & 4 & $\mathrm{p}=1.0$ \\
\hline History of urethritis after catheterization & 1 & 1 & $\mathrm{p}=1.0$ \\
\hline Cigarette smoking & 6 & 7 & $\mathrm{p}=0.762$ \\
\hline Benign prostatic hyperplasia & 7 & 5 & $\mathrm{p}=0.754$ \\
\hline Total Mixed Comorbidities & 11 & 10 & $\mathrm{p}=0.800$ \\
\hline
\end{tabular}




\section{Evaluation of Treatment Results (see Tables 2-4)}

Intergroup analysis revealed statistically significant differences in terms of improvement of penile pain, effective plaque size reduction, improvement of penile curvature and effective improvement of erectile function index score.

In group $A$, after treatment of 6 months, penile pain disappeared in $80 \%$ of the cases while in group B pain disappeared in $12.5 \% \quad(\mathrm{p}<0.0001)$; in group $\mathrm{A}$, after treatment of 18 months, penile pain disappeared in all cases while in group B pain disappeared only in $25 \%$ of the cases $(\mathrm{p}<0.0001)$.

In group A, after treatment of 6 and 18 months, in all cases occurred a reduction of plaque size, while in group B it never occurred $(\mathrm{p}<0.0001)$. In group $A$, after treatment of 6 months, the change in penile plaque size consisted in a reduction of plaque volume $=-47.6 \%$ while in group $B$ the change consisted in an increase in plaque volume $=+55.7 \%$ $(\mathrm{p}=0.000)$; in group $\mathrm{A}$, after treatment of 18 months, the change in penile plaque size consisted in a reduction of plaque volume $=-73.6 \%$ while in group $B$ the change consisted in an increase in plaque volume $=+118.7 \%$ $(p=0.000)$.

In group A, after treatment of 6 and 18 months, worsening of penile curvature never occurred while in group $\mathrm{B}$ this worsening occurred in $78.3 \%$ and $86.4 \%$ of the cases respectively $(\mathrm{p}<0.0001)$.

In group $A$, after treatment of 6 and 18 months, the improvement of curvature occurred in $76.3 \%$ and $81.5 \%$ of the cases respectively while in group B occurred only in
$2.7 \%$ and $8.1 \%$ of the cases respectively $(\mathrm{p}<0.0001)$. Moreover, in group A, after treatment of 6 months, the mean curvature decrease was $-11.03^{\circ}$ while in group B the mean curvature decrease was $-5^{\circ}(\mathrm{p}=0.337)$. Furthermore, in group A, after treatment of 18 months, the mean curvature decrease was $-16.7^{\circ}$ while in group $B$ the mean curvature decrease was $-4^{\circ}(p=0.019)$.

In group $A$, after treatment of 6 and 18 months, in PD patients with ED the restoration of rigid erection occurred for most of the cases in $60.0 \%$ and $70.0 \%$ respectively, while in group $B$ it never occurred $(p=0.003$ and $p=0.001$ respectively). Otherwise, in group $B$ and in $P D$ patients without ED, after treatment of 6 and 18 months an erectile deficiency occurred in $50.0 \%$ and $60.0 \%$ of the cases respectively, while in group A this occurrence never occurred $(p<0.0001)$. No cases of hypotension or heart rhythm disorder occurred during the treatment. Drug-related adverse effects did not occur in treated patients and no patient discontinued treatment. In 2 patients $(4.8 \%)$ occurred a rash of penile skin, approximately after one month of application of topical 4\% Diclofenac and then, after a short period of interruption the drug was replaced with topical $2 \%$ Diclofenac without subsequent local reactions.

\section{DISCUSSION AND CONCLUSIONS}

Verapamil is a slow calcium channel blocker that reduces the proliferation of fibroblasts and the local production of extracellular matrix (by fibroblasts); it also increases the local activity of collagenase and it affects the cytokine regulation of fibroblasts reducing the excess production of

Table 2. Outcomes After 6-Month Treatment

\begin{tabular}{|c|c|c|c|}
\hline Studied Patterns & $\begin{array}{l}\text { Group A } \\
\text { Treated Group }\end{array}$ & $\begin{array}{c}\text { Group B } \\
\text { Control Group }\end{array}$ & $\begin{array}{l}\text { Statistical Analysis } \\
\text { p-Value }\end{array}$ \\
\hline & \multicolumn{3}{|c|}{ After 6 Months } \\
\hline Penile Pain Disappearance mean rate $\%$ / n. patients / total patients & $80.0(20 / 25)$ & $12.5(3 / 24)$ & $\mathrm{p}<0.0001\left(\chi^{2}\right.$ test $)$ \\
\hline Appearance of Penile Pain mean rate $\%$ / n. patients / total patients & $0(0 / 16)$ & $35.29(6 / 17)$ & $\mathrm{p}=0.018\left(\chi^{2}\right.$ test $)$ \\
\hline Reduction of Plaque Size mean rate $\%$ / n. patients / total patients & $100.0(41 / 41)$ & $0(0 / 41)$ & $\mathrm{p}<0.0001\left(\chi^{2}\right.$ test $)$ \\
\hline Change in Penile Plaque Volume mean rate $\%+$ Standard Deviation & $-47.69 \pm 20.6$ & $+55.76 \pm 80.67$ & $\mathrm{p}=0.000(\mathrm{ANOVA})$ \\
\hline Disappearance of the Plaque mean rate $\% / n$. patients / total patients & $2.43(1 / 41)$ & $0(0 / 41)$ & $\mathrm{p}=0.314\left(\chi^{2}\right.$ test $)$ \\
\hline Reduction of Penile Calcification Size mean rate $\% / \mathrm{n}$. patients / total patients & $100.0(16 / 16)$ & $0(0 / 15)$ & $\mathrm{p}<0.0001\left(\chi^{2}\right.$ test $)$ \\
\hline Change in Penile Calcification Volume mean rate $\%+$ Standard Deviation & $-58.51 \pm 25.89$ & $+161.52 \pm 148.49$ & $\mathrm{p}=0.000(\mathrm{ANOVA})$ \\
\hline Disappearance of the Calcification mean rate $\% / n$. patients / total patients & $12.5(2 / 16)$ & $0(0 / 15)$ & $\mathrm{p}=0.483\left(\chi^{2}\right.$ test $)$ \\
\hline Appearance of New Calcification mean rate $\% / \mathrm{n}$. patients / total patients & $0.0(0 / 41)$ & $9.75(4 / 41)$ & $\mathrm{p}=0.115\left(\chi^{2}\right.$ test $)$ \\
\hline Improvement of Penile Curvature mean rate $\% / \mathrm{n}$. patients / total patients & $76.31(29 / 38)$ & $2.7(1 / 37)$ & $\mathrm{p}<0.0001(\chi 2$ test $)$ \\
\hline $\begin{array}{l}\text { Decrease of Penile Curvature Angle average - degrees } \\
+ \text { Standard Deviation }+ \text { n. patients / total patients }\end{array}$ & $-11.03^{\circ} \pm 6.07(29 / 38)$ & $-5.0^{\circ} \pm 0(1 / 37)$ & $\mathrm{p}=0.337(\mathrm{ANOVA})$ \\
\hline $\begin{array}{l}\text { Percentage Reduction of the Penile Curvature } \\
\text { Angle mean rate } \%+\text { Standard Deviation }+n \text {. patients / total patients }\end{array}$ & $-40.5 \pm 20.71(29 / 38)$ & $-11.11 \pm 0(1 / 37)$ & $\mathrm{p}=0.174(\mathrm{ANOVA})$ \\
\hline Penile Curvature Unchanged mean rate $\% / \mathrm{n}$. patients / total patients & $23.68(9 / 38)$ & $18.91(7 / 37)$ & $\mathrm{p}=0.779\left(\chi^{2}\right.$ test $)$ \\
\hline Disappearance of the Curvature mean rate $\% / \mathrm{n}$. patients / total patients & $2.63(1 / 38)$ & $0(0 / 37)$ & $\mathrm{p}=0.320\left(\chi^{2}\right.$ test $)$ \\
\hline Worsening of Penile Curvature mean rate $\% / \mathrm{n}$. patients / total patients & $0(0 / 38)$ & $78.37(29 / 37)$ & $\mathrm{p}<0.0001(\chi 2$ test $)$ \\
\hline Appearance of New Penile Curvature mean rate $\% / \mathrm{n}$. patients / total patients & $0(0 / 3)$ & $50.0(2 / 4)$ & $\mathrm{p}=0.428\left(\chi^{2}\right.$ test $)$ \\
\hline
\end{tabular}


Table 3. Outcomes After 18-Month Treatment

\begin{tabular}{|c|c|c|c|}
\hline Studied Patterns & $\begin{array}{l}\text { Group A } \\
\text { Treated Group }\end{array}$ & $\begin{array}{c}\text { Group B } \\
\text { Control Group }\end{array}$ & $\begin{array}{l}\text { Statistical Analysis } \\
\text { p-Value }\end{array}$ \\
\hline & \multicolumn{3}{|c|}{ After 18 Months } \\
\hline Penile Pain Disappearance mean rate $\%$ / n. patients / total patients & $100.0(25 / 25)$ & $25.0(6 / 24)$ & $\mathrm{p}<0.0001(\chi 2$ test $)$ \\
\hline Appearance Of Penile Pain mean rate $\% / n$. patients / total patients & $0(0 / 16)$ & $47.05(8 / 17)$ & $\mathrm{p}=0.0027(\chi 2$ test $)$ \\
\hline Reduction Of Plaque Size mean rate $\%$ / n. patients / total patients & $100.0(41 / 41)$ & $0(0 / 41)$ & $\mathrm{p}<0.0001(\chi 2$ test $)$ \\
\hline Change in Penile Plaque Volume mean rate $\%+$ Standard Deviation & $-73.6 \pm 18.407$ & $+118.74 \pm 186.09$ & $\mathrm{p}=0.000(\mathrm{ANOVA})$ \\
\hline Disappearance of the Plaque mean rate $\% / n$. patients / total patients & $7.31(3 / 41)$ & $0(0 / 41)$ & $\mathrm{p}=0.239\left(\chi^{2}\right.$ test $)$ \\
\hline Reduction of Penile Calcification Size mean rate $\% / \mathrm{n}$. patients / total patients & $100.0(16 / 16)$ & $0(0 / 15)$ & $\mathrm{p}<0.0001(\chi 2$ test $)$ \\
\hline Change in Penile Calcification Volume mean rate $\%+$ Standard Deviation & $-75.21 \pm 25.85$ & $+208.0 \pm 132.79$ & $\mathrm{p}=0.000(\mathrm{ANOVA})$ \\
\hline Disappearance of the Calcification mean rate $\% / \mathrm{n}$. patients / total patients & $31.25(5 / 16)$ & $0(0 / 15)$ & $\mathrm{p}=0.0434\left(\chi^{2}\right.$ test $)$ \\
\hline Appearance of New Calcification mean rate $\% / \mathrm{n}$. patients / total patients & $0.0(0 / 41)$ & $29.26(12 / 41)$ & $\mathrm{p}=0.0002(\chi 2$ test $)$ \\
\hline Improvement of Penile Curvature mean rate $\% / \mathrm{n}$. patients / total patients & $81.57(31 / 38)$ & $8.1(3 / 37)$ & $\mathrm{p}<0.0001\left(\chi^{2}\right.$ test $)$ \\
\hline $\begin{array}{l}\text { Decrease of Penile Curvature Angle average - degrees } \\
+ \text { Standard Deviation }+n \text {. patients / total patients }\end{array}$ & $-16.74^{\circ} \pm 8.75(31 / 38)$ & $-4.0^{\circ} \pm 4.24(3 / 37)$ & $\mathrm{p}=0.019(\mathrm{ANOVA})$ \\
\hline $\begin{array}{l}\text { Percentage Reduction of the Penile Curvature Angle mean rate } \% \\
+ \text { Standard Deviation }+n \text {. patients / total patients }\end{array}$ & $-58.42 \pm 24.25(31 / 38)$ & $-28.33 \pm 8.32(3 / 37)$ & $\mathrm{p}=0.043(\mathrm{ANOVA})$ \\
\hline Penile Curvature Unchanged mean rate $\% / n$. patients / total patients & $18.42(7 / 38)$ & $5.4(2 / 37)$ & $\mathrm{p}=0.152\left(\chi^{2}\right.$ test $)$ \\
\hline Disappearance of the Curvature mean rate $\% / n$. patients / total patients & $7.89(3 / 38)$ & $0(0 / 37)$ & $\mathrm{p}=0.240\left(\chi^{2}\right.$ test $)$ \\
\hline Worsening of Penile Curvature mean rate $\% / n$. patients / total patients & $0(0 / 38)$ & $86.48(32 / 37)$ & $\mathrm{p}<0.0001(\chi 2$ test $)$ \\
\hline Appearance of New Penile Curvature mean rate $\% / \mathrm{n}$. patients / total patients & $0(0 / 3)$ & $100.0(4 / 4)$ & $\mathrm{p}=0.0286(\chi 2$ test $)$ \\
\hline
\end{tabular}

fibrogenic cytokines [22]. Iontophoresis (electromotive drug administration/EMDA) is a non-invasive treatment for drug administration without the use of injections and the patient can autonomously perform this therapy. Levine (2003) who measured the levels of Verapamil in the tunica albuginea in patients, after surgical treatment of $\mathrm{PD}$, showed that the Verapamil was detected in $71.5 \%$ of the tunica albuginea specimens after iontophoresis administration with a wide range of drug levels [23].

Antioxidants may play an important role in medical treatment of PD because the accumulation of activated inflammatory cells in PD leads to the production of ROS [6].

Vitamin $E$ was the first oral therapy proposed for the treatment of PD; it is a potent antioxidant that is thought to reduce collagen deposits within the tunica albuginea. It interacts with hydroxyl radical (hydroxide, the more damaging ROS) donating a hydrogen atom to restore the molecule to normal inert state [6]. Some studies have found that Vitamin $\mathrm{E}$ and its metabolites have an anti-inflammatory and anti-COX2 property [24]. Our recent studies have evaluated and verified the effectiveness of Vitamin $\mathrm{E}$ in combination with other substances [13].

Flavonoids have been found to have anti-inflammatory and antioxidant activity $[25,26]$. The components of propolis, caffeic acid phenethyl ester and terpenoids inhibit

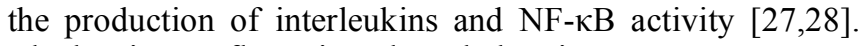
Blueberries are flowering plants belonging to Vaccinium spp. (Ericaceae). This fruit contain anthocyanins, polyphenols and flavonoids and appear to have the highest antioxidant capacity among common fruits and vegetables; blueberries may also cure chronic diseases through anti-inflammatory and anti-fibrotic effect mechanisms. Blueberry anthocyanins are able to inhibit NF-KB, iNOS and COX-2 expression [29].

Diclofenac: the properties of NSAID's, including the anti-inflammatory activity of Diclofenac, are already known. moreover, it has already been used in the multimodal treatment of PD [13].

The significant improvements obtained in group A concern the basic parameters of the disease: plaque size, degree of penile curvature and penile rigidity and if erectile dysfunction was present. Interestingly and in contrast to the current medical opinion was to observe a significant decrease of calcification volume and even the possibility of determining its disappearance in $31.2 \%$ of the cases, after 18 months of treatment.

In non-treated group, only few cases where the curvature was improved $(8.1 \%=3$ cases / after 18 months), in reality, the disease had progressed as shown by the ultrasound study that found always an increase in plaque volume ( $\mathrm{n} \# 1$ case: 1.0 to $1.3 \mathrm{~cm}^{3} ; \mathrm{n \# 2}$ case: 2.1 to $2.4 \mathrm{~cm}^{3}$; $\mathrm{n} \# 3$ case: 1.1 to 1.2 $\mathrm{cm}^{3}$ ). In these three patients their deformity improved because PD (inflammatory zone) had progressed locally causing a reduction of elasticity and expandability of involved cavernous tissue; these new changes of the architectural structure of the penis led to a paradoxical improvement of curvature.

Recently it has been reported that without any treatment the penile pain seems to resolve spontaneously within $12-18$ 
Table 4. Outcomes on Penile Rigidity After 6- and 18-Month Treatment

\begin{tabular}{|c|c|c|c|c|c|c|}
\hline Studied Patterns & $\begin{array}{l}\text { Group A } \\
\text { Treated } \\
\text { Group }\end{array}$ & $\begin{array}{l}\text { Group B } \\
\text { Control } \\
\text { Group }\end{array}$ & $\begin{array}{l}\text { Statistical } \\
\text { Analysis } \\
\text { p-Value }\end{array}$ & $\begin{array}{l}\text { Group A } \\
\text { Treated } \\
\text { Group }\end{array}$ & $\begin{array}{l}\text { Group B } \\
\text { Control } \\
\text { Group }\end{array}$ & $\begin{array}{c}\text { Statistical } \\
\text { Analysis } \\
\text { p-Value }\end{array}$ \\
\hline & \multicolumn{3}{|c|}{ After 6 Months } & \multicolumn{3}{|c|}{ After 18 Months } \\
\hline $\begin{array}{l}\text { Improvement of Penile Rigidity in all patients } \\
\text { mean rate } \% / \mathrm{n} \text {. patients / total patients }\end{array}$ & $73.17(31 / 41)$ & $0(0 / 41)$ & $\mathrm{p}<0.0001$ ( $\chi^{2}$ test) & $78.04(32 / 41)$ & $0(0 / 41)$ & $\mathrm{p}<0.0001$ ( $(2$ test $)$ \\
\hline $\begin{array}{l}\text { Restoration of Rigid Erection in patients } \\
\text { with Erectile Dysfunction mean rate \% / } \\
\text { n. patients / total patients }\end{array}$ & $60.0(6 / 10)$ & $0(0 / 11)$ & $\mathrm{p}=0.003$ ( $\chi^{2}$ test $)$ & $70.0(7 / 10)$ & $0(0 / 11)$ & $\mathrm{p}=0.001(\chi 2$ test $)$ \\
\hline $\begin{array}{l}\text { Appearance of Erectile Dysfunction mean } \\
\text { rate } \% / \mathrm{n} \text {. patients / total patients }\end{array}$ & $0(0 / 31)$ & $50.0(15 / 30)$ & $\mathrm{p}<0.0001\left(\chi^{2}\right.$ test $)$ & $0(0 / 31)$ & $60.0(18 / 30)$ & $\mathrm{p}<0.0001$ ( $\chi^{2}$ test $)$ \\
\hline \multicolumn{7}{|l|}{$\begin{array}{l}\text { Change in "Erectile Function Index Score" } \\
\text { in Different Classes of Patients: } \downarrow\end{array}$} \\
\hline $\begin{array}{l}\text { In all patients (excluding Erectile } \\
\text { Dysfunction) IIEF-mean score + } \\
\text { Standard Deviation + (n. patients) }\end{array}$ & $+0.67 \pm 0.47(31)$ & $-1.23 \pm 1.30(30)$ & $\mathrm{p}=0.000($ ANOVA $)$ & $+0.7 \pm 0.46(31)$ & $-2.53 \pm 2.45(30)$ & $\mathrm{p}=0.000(\mathrm{ANOVA})$ \\
\hline $\begin{array}{l}\text { In patients with Erectile Dysfunction } \\
\text { IIEF - mean score }+ \text { Standard Deviation }+ \\
\text { (n. patients) }\end{array}$ & $+4.9 \pm 2.02(10)$ & $-0.54 \pm 0.93(11)$ & $\mathrm{p}=0.000(\mathrm{ANOVA})$ & $+5.1 \pm 2.02(10)$ & $-0.63 \pm 1.12(11)$ & $\mathrm{p}=0.000($ ANOVA $)$ \\
\hline
\end{tabular}

months in the majority of patients [11]. In contrast, we found only $25 \%$ of the non-treated PD patients resolved penile pain spontaneously at follow-up (18 months). Observing the high rates of disease worsening after 18 months in non-treated group $\mathrm{B}$, we can affirm that $\mathrm{PD}$ is certainly a progressive disease and it does not spontaneously heal.

Although vitamin E monotherapy is ineffective to treat PD [11] the present study and other published results [13, 30] reported better results when vitamin E was administered in combination with another substance in PD treatment (combined-multimodal treatment). We beleive that any antioxidant would be more effective when is combined with other drugs, but this consideration should be also true to any substance in the medical management of PD. Our findings confirm and support that the best approach for treating PD is "multimodal therapy" [31, 32], because it was able to achieve greater results than any single drug alone.

Our results showed that long-term multimodal treatment with Verapamil associated with Antioxidants and topical Diclofenac is statistically and significantly effective in treating PD, whereas, lower therapeutic responses were obtained after 6 months (medium-term treatment), also considering the "natural history" of PD [33].

Verapamil is more effective when the treatment program includes both routes of administration: peri-lesional injection + iontophoresis $[13,34]$. Iontophoresis is a safe and noninvasive treatment for drug administration and the patient can autonomously perform this therapy; since home therapy is expected to be a long-time treatment, the patient may directly buy or rent the appropriate equipment. Good results were achieved only after 6 months of treatment and this may explain why in other reported studies, using the same drugs but with a shorter time limit of the treatment, showed less satisfactory results. In case the option for conservative therapy exists, as PD is a chronic illness, short-term therapies should therefore be avoided. The various parameters of PD, especially penile curvature, plaque size and penile rigidity, should always be evaluated by standardized instruments: penile dynamic ultrasound examinations, IIEF questionnaires, serial photographs of the curvature and pain scales for pain measurement. Surely, in order to be more reliable, these studies will need to use not only with subjective parameters but mainly with safe diagnostic tools. To evaluate the efficacy of a conservative procedure for the treatment of $\mathrm{PD}$, more prospective, randomized and placebo-controlled studies are needed.

\section{CONFLICT OF INTEREST}

The authors declare that they do not have any conflict of interest.

\section{ACKNOWLEDGEMENTS}

Declared none.

\section{REFERENCES}

[1] Schwarzer, U.; Sommer, F.; Klotz, T.; Braun, M.; Reifenrath, B.; Engelmann, U. The prevalence of Peyronie's disease: results of a large survey. B. J. U. Int., 2001, 88, 727-730.

[2] Dibenedetti, D.B.; Nguyen, D.; Zografos, L.; Ziemiecki, R.; Zhou, X.A. Population-Based Study of Peyronie's Disease: Prevalence and Treatment Patterns in the United States. Adv. Urol., 2011, DOI: $10.1155 / 2011 / 282503$.

[3] Devine, C.J. Jr.; Somers, K.D.; Jordan, G.H.; Schlossberg, S.M. Proposal: trauma as the cause of the Peyronie's lesion. J. Urol., 1997, 157, 285-290.

[4] Somers, K.D.; Dawson, D.M. Fibrin deposition in Peyronie's disease plaque. J. Urol., 1997, 157, 311-315.

[5] Gonzalez-Cadavid, N.F.; Magee, T.R.; Ferrini, M.; Qian, A. Vernet, D.; Rajfer, J. Gene expression in Peyronie's disease. Int. J. Impot. Res., 2002, 14, 361-374.

[6] Sikka, S.C.; Hellstrom, W.J.G. Role of oxidative stress and antioxidants in Peyronie's disease. Int. J. Impot. Res., 2002, 14, 353-360.

[7] Paulis, G.; Brancato, T. Inflammatory mechanisms and oxidative stress in Peyronie's disease. Therapeutic "rationale" and related emerging treatment strategies. Inflamm. Allergy Drug Targets, 2012, 11, 48-57.

[8] Kendirci, M.; Hellstrom, W.J. Critical analysis of surgery for Peyronie's disease. Curr. Opin. Urol., 2004, 14, 381-388. 
[9] Hatzimouratidis, K.; Eardle, I.; Giuliano. F.; Hatzichristou, D.; Moncada, I.; Salonia, A.; Vardi, Y.; Wespes, E. EAU Guidelines on Penile Curvature. Eur. Urol., 2012, 62, 543-552.

[10] Kadioglu, A.; Akman, T.; Sanli, O.; Gurkan, L.; Cakan, M.; Celtik, M. Surgical treatment of Peyronie's disease: a critical analysis. Eur. Urol., 2006, 50, 235-248.

[11] Hauck, E.W.; Diemer, T.; Schmelz, H.U.; Weidner. W. A critical analysis of nonsurgical treatment of Peyronie's disease. Eur. Urol., 2006, 49, 987-997.

[12] Safarinejad, M.R.; Asgari, M.A.; Hosseini, S.Y.; Dadkhah, F. A double-blind placebo-controlled study of the efficacy and safety of pentoxifylline in early chronic Peyronie's disease. B. J. U. Int., 2010, 106, 240-248.

[13] Paulis, G.; Brancato, T.; D'Ascenzo, R.; De Giorgio, G.; Nupieri, P.; Orsolini, G.; Alvaro, R. Efficacy of vitamin E in the conservative treatment of Peyronie's disease: legend or reality? A controlled study of 70 cases. Andrology, 2013, 1, 120-128.

[14] Echizen, H.; Vogelgesang, B.; Eichelbaum, M. Effects of d,1verapamil on atrioventricular conduction in relation to its stereoselective first-pass metabolism. Clin. Pharmacol. Ther., $\mathbf{1 9 8 5}, 38,71-76$.

[15] Kelâmi, A. Autophotography in evaluation of functional penile disorders. Urology, 1983, 21, 628-629.

[16] Farrar, J.T.; Young, J.P. Jr.; LaMoreaux, L.; Werth, J.L.; Poole, R.M. Clinical importance of changes in chronic pain intensity measured on an 11-point numerical pain rating scale. Pain, 2001, 94, 149-158.

[17] Rosen, R.C.; Riley, A.; Wagner, G.; Osterloh, I.H.; Kirkpatrick, J.; Mishra, A. The international index of erectile function (IIEF): a multidimensional scale for assessment of erectile dysfunction. Urology, 1997, 49, 822-830.

[18] Prando, D. New sonographic aspects of peyronie disease. $J$. Ultrasound. Med., 2009, 28, 217-232.

[19] Mitchell, C.; Winter, T. Renal Transplants. In: Clinical Sonography - a pratical guide; Sanders, R.C., Winter, T.C., Eds.; Lippincott Williams \& Wilkins: Baltimore, 2007, p 212.

[20] Behre, H.M.; Zitzmann, M. Imaging Diagnostics. In: AndrologyMale Reproductive Health and Dysfunction; Nieschlag, E., Behre, H.M., Nieschlag, S., Eds.; Springer-Verlag: Berlin Heidelberg, 2010, p 101.

[21] Kim, C.K.; Cho, J.Y. Prostate. In: Uroradiology; Kim, S.H. Ed.; Springer-Verlag: Berlin Heidelberg, 2012, p. 826.

[22] Levine, L.A.; Estrada, C.R. Intralesional verapamil for the treatment of Peyronie's disease: a review. Int. J. Impot. Res., 2002, $14,324-328$.
[23] Levine, L.A.; Estrada, C.R.; Shou, W.; Cole, A. Tunica albuginea tissue analysis after electromotive drug administration. J. Urol., 2003, 169, 1775-1778

[24] O'Leary, K.A.; de Pascual-Tereasa, S.; Needs, P.W.; Bao, Y.P.; O'Brien, N.M.; Williamson, G. Effect of flavonoids and vitamin E on cyclooxygenase-2 (COX-2) transcription. Mutat. Res., 2004, 551, 245-254.

[25] Rathee, P.; Chaudhary, H.; Rathee, S.; Rathee, D.; Kumar, V.; Kohli, K. Mechanism of action of flavonoids as anti-inflammatory agents: a review. Inflamm. Allergy Drug Targets, 2009, 8, 229-235.

[26] Chirumbolo, S. The role of quercetin, flavonols and flavones in modulating inflammatory cell function. Inflamm. Allergy Drug Targets, 2010, 9, 263-285

[27] Marquez, N.; Sancho, R.; Macho, A.; Calzado, M.A.; Fiebich, B.L.; Munoz, E. Caffeic acid phenethyl ester inhibits T-cell activation by targeting both nuclear factor of activated T-cells and NF-kappaB transcription factors. J. Pharmacol. Exp. Ther., 2004, 308, 993-1001.

[28] de las Heras, B.; Hortelano, S. Molecular basis of the antiinflammatory effects of terpenoids. Inflamm. Allergy Drug Targets, 2009, 8, 28-39.

[29] Wang, Q.; Xia, M.; Liu, C.; Guo, H.; Ye, Q.; Hu, Y.; Zhang, Y.; Hou, M.; Zhu, H.; Ma, J.; Ling, W. Cyanidin-3-O-beta-glucoside inhibits iNOS and COX-2 expression by inducing liver X receptor alpha activation in THP-1 macrophages. Life Sci., 2008, 83, 176184.

[30] Safarinejad, M.R.; Hosseini, S.Y.; Kolahi, A.A. Comparison of vitamin $\mathrm{E}$ and propionyl-L-carnitine, separately or in combination, in patients with early chronic Peyronie's disease: A double-blind, placebo controlled, randomized study. J. Urol., 2007, 178, 13981403.

[31] Cortés-González, J.R.; Glina, S. Conservative treatment of Peyronie's disease: colchicine $v s$ colchicine plus vitamin E. Actas Urol. Esp., 2010, 34, 444-449.

[32] Kuehhas, F.E.; Weibl, P.; Georgi, T.; Djakovic, N.; Herwig, R. Peyronie's Disease: Nonsurgical Therapy Options. Rev. Urol., 2011, 13, 139-146.

[33] Paulis, G.; Cavallini, G. Clinical evaluation of natural history of Peyronie's disease: our experience, old myths and new certainties. Inflamm. Allergy Drug Targets, 2013, 12, 341-348.

[34] Paulis, G.; Cavallini, G.; Brancato, T.; Alvaro, R. PeironimevPlus $®$ in the treatment of chronic inflammation of tunica albuginea (Peyronie's disease). Results of a controlled study. Inflamm. Allergy Drug Targets, 2013, 12, 61-67. 